\title{
Adherence to the treatment of hypertension: influence of public health capacities
}

\begin{abstract}
The present article was elaborated on the basis of an exhaustive theoretical review in an Institution of Health Service Delivery Level II of the Cauca Valley Colombia. Hypertension is defined as a non communicable chronic disease cataloged as a priority in public health, the methodology of the problem is applied, whose final result establishes for this institution a "Lack of adherence to the treatment of hypertensive patients" derived from the absence of a stable public policy against minimum capacities to maintain it. The analysis of public health capacities with the text of the initiative "Public Health in the Americas" is defined as the "set of stable and interconnected means by which public health activities are organized". The present article aims to describe the different interconnections given to the adherence to treatment for hypertensive patients of a Health Service Delivery Institution Level II is the most appropriate to the required public health capacities and provides open dialogues to the critical to reflect and adjust processes that approach the referred initiative
\end{abstract}

Keywords: hypertension, adherence to treatment, capacities, public health
Volume 2 Issue 5 - 2018

\author{
Raúl Arturo Lasso López \\ Doctorante Educación/Magister en Salud Pública / Médico y \\ Cirujano, Universidad del Cauca, Colombia
}

\begin{abstract}
Correspondence: Raúl Arturo Lasso López, Doctorante Educación/Magister en Salud Pública/Médico y Cirujano Universidad de Baja California, Baja California-México/ Universidad del Valle, Cali-Colombia/Universidad del Cauca, Popayán- Colombia, Calle 3I Norte No. 13 - I 10 Casa 30 Conjunto Residencial Vallerobledo Popayán Cauca Colombia Tel 3006444916,Email arturolasso I@gmail.com
\end{abstract}

Received: August 03, 20I8 | Published:September II, 2018

\section{Introduction}

Chronic non communicable diseases represent the leading cause of death and disability in people of productive age in the world. Developing countries face the growing burden of non communicable diseases - NCDs - which are expected to increase considerably in the next 20 years. Cardiovascular diseases have increased markedly because of the changes in life caused by industrialization that triggers problems such as hypertension, responsible for $44 \%$ of deaths in men and women under 70 years of age in Latin America and the Caribbean. Like the world situation, in Colombia cardiovascular diseases cular diseases, mainly ischemic heart disease, cerebrovascular disease and hypertension. With its complications, occupy the first place followed by cancer that has registered an important increase tante. With this panorama at world and national level it is worrisome that in spite of implementing a series of actions of proven effectiveness the hypertension programs do not reach the expected achievements in terms of recovering health, several causes determine this situation among them an inadequate control of the blood pressure figures, the lack of opportunity in the allocation of appointments and authorization of medications, the therapeutic non-compliance caused by the ignorance of the complications of the disease, forgetting in the taking of medicines among others, resulting according to several researchers compliance of the treatment of arterial hypertension as a great challenge of the health organisms. According to the $\mathrm{WHO}$ analysis, ${ }^{1}$ only $50 \%$ of chronic patients comply with their treatments in developed countries, therefore, this situation is worse in developing countries, given the conditions of scarce resources and inequities which lead to the increase in risk of complications, sequelae or premature death. From a financial perspective, it represents an expenditure of resources in the production and delivery of medicines that the patient does not consume or use properly. These premises give grounds to assume hypertension as a chronic disease involving a serious public health problem, for searching and generates $\mathrm{r} r$ investigative and intervention strategies linking long - term actions hypertensive patients.

\section{Methods and data collection}

The study was elaborated on the basis of an exhaustive theoretical review in an Institution of Health Service Delivery Level II of the Cauca Valley Colombia. Related information was collected with the lack of adherence to treatment of hypertensive patients IPS. The literature search was carried out through PubMed and Google Scholar. Articles and sources that oriented statistics related to the prevalence, complications and adherence to the treatment of arterial hypertension, likewise a key source were the documents of the WHO and PAHO related to the capacities in public health, specifically those parts of the Americas. It highlights the local information of the Ministry of Health of Colombia mainly related to care guidelines for hypertensive and statistical data provided through the Administrative Department of Cali Valley Planning. For the diagnosis of situation in the IPS Level II, it was followed: Problem tree, objectives tree, problem prioritization, interest analysis matrix and logical framework matrix employees for data collection and processing

\section{Results}

\section{Presentation of the institution (context):}

The Institution for the provision of health services Level II - IPS Level II- of care is located in the Tequendama neighborhood south of the city of Cali in the department of Valle del Cauca - Colombia. This city was founded on July 25 of 1536, has an area of $561,66-\mathrm{km}^{2} \mathrm{~h}-$, with an average elevation of $1.070 \mathrm{~m}$ above sea level, an average $25.5^{\circ} \mathrm{C}$ temperature, a population of $2.420 .114-2017$-Habitatives, and a gross density of 43.20 , the city is located geographically in the valley Cauca River, Administrative Department of Planning. (2016). The western part of the city is guarded by the famous Farallones de Cali, which are part of the Western Cordillera of the Colombian Andes. See Table 1. The IPS Level II chosen for the article, is contracted by a Promoting Health Services Company -EPS- of the contributory regime, meets the requirements for operation - habilitation- for the provision of services of First Level of Care, where for the month of 
August 2017, 7 had a population assigned to attend 46308 users, of which 14564 were dependent contributors, and 3351 hypertensive users, identified and diagnosed, which corresponds to $7.24 \%$ of the population to be served. The I PS Level II has a population pyramid with a narrow base configuration, in the extremes with predominance of the female population and of the age range of 30 to 34 years in both genders. It presents a total per capita of $\$ 86.710$ with a Pos item of $\$ 79,179$ and No Pos of $\$ 7.531$, which is equivalent to $173 \%$ execution above the target see Figure 1. Important res altar that the EPS to which are affiliated s users structure their plan strategic since under the National Development Plan and articulates with the ratégico Est Plan Contracted IPS and thus assigns the population to be served in IPS Level II as follows: stratum levels for occupied housing 1 and 2 $70 \%$ and the remainder for strata 3 Y 4 that is to say 30\% - Source: Registration of affiliation data of the IPS Level II 2017-. To access the provision of health services, the population has a call center - C all Center - or it also uses direct quotes in the institution. For both cases checking software rights provided by the EPS is queried, it has further bases registration ipertensos patients $h$. Regarding the level of education of the population assigned to the IPS I I is as follows:

I. $15.3 \%$ they do not have any degree of schooling

II. $55.5 \%$ has $\mathrm{n}$ completed basic education

III. $0.2 \%$ they have a technical or commercial school with primary school completed

IV. $16.6 \%$ Completed upper secondary education

V. $11.7 \%$ Completed higher education

VI. $0.7 \%$ not specified

Table I Geographic situation, area and climate 20I5-20I6 Cali Colombia

\begin{tabular}{|c|c|}
\hline Description & Valor \\
\hline Latitud norte & 3'27'26- \\
\hline Longitud oeste (I'vlendiano de Greenwich) & 76 '3/'42" \\
\hline $\begin{array}{l}\text { Altura sabre el nivel del rnar (rn) (Coordenadas } \\
\text { I I0.0DON, I I0.000E) }\end{array}$ & $\mathrm{I}, 070$ \\
\hline Altura maxima $(\mathrm{m})$ (Farallones) & 4,070 \\
\hline Altura minima $(\mathrm{m})$ (Oriente) & 950 \\
\hline Superficie total del Municipio $\left(\mathrm{km}^{2}\right)$ & 561.7 \\
\hline Comunas $\left(\mathrm{km}^{2}\right)$ & 120.4 \\
\hline Corregimientos $\left(\mathrm{km}^{2}\right)$ & 424.4 \\
\hline Expansion urtana $\left(\mathrm{km}^{2}\right)$ & 16.3 \\
\hline Protecciitin Rio Cauca K I - K 7L $\left(\mathrm{km}^{2}\right)$ & 0.5 \\
\hline Suelo urban ${ }^{\circ}\left(\mathrm{km}^{2}\right)$ & 119.2 \\
\hline Suelo de expansitin $\left(\mathrm{km}^{2}\right)$ & 16.3 \\
\hline Suelo rural $\left(\mathrm{km}^{2}\right)$ & 426.1 \\
\hline Temperatura prornedio $(\mathrm{T})$ & 25.5 \\
\hline Precipitacin anual (mm) & 752 \\
\hline Hurnedad relaiiva media anual (\%) & 66.6 \\
\hline
\end{tabular}

Source: IGAC, DAP, CVC, IDEAM

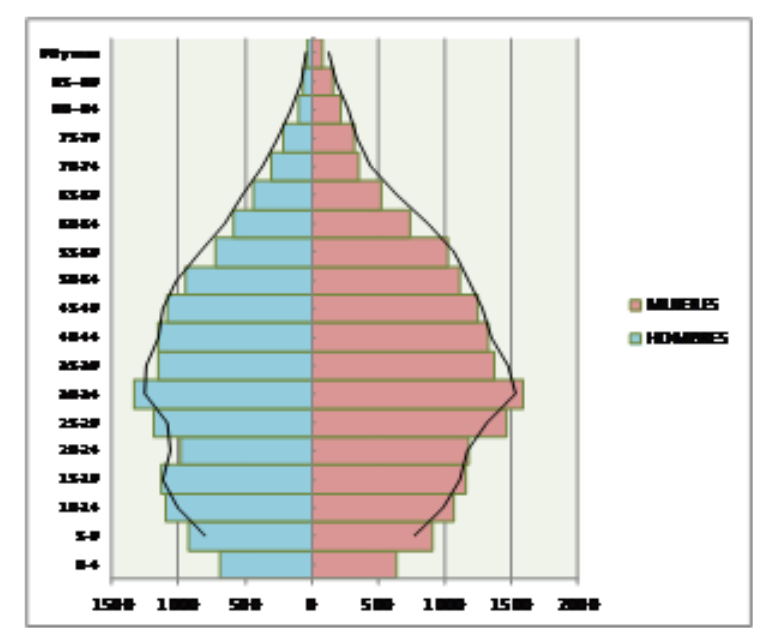

Figure I Population Pyramid IPS Level II of Attention 2017.

Source: Statistics I PS Level II Attention 2017

\section{Services briefcase}

The I PS Level II object of the present analysis is duly registered in the Special Registry of Providers of health services of the Ministry of Health REPS, has the following services: Medical specialist - Gynecology, Internal Medicine, Pediatrics and General Surgery - General Medicine, minor procedures, nursing programs, program promotion and prevention, dentistry and oral hygiene. Appointments are assigned through a Call Center with hours from Monday to Saturday from 7:00 am to 7:00 pm. The Arterial Hypertension program works with hours from Monday to Friday from 7:00 am to $1: 00 \mathrm{pm}$.

\section{Description of the priority in public health to be analyzed}

Having as a framework the essential public health function: Development of policies and institutional capacity of planning and management in public health, in accordance with decree 3039 of 2007 and resolution 425 of 2008, the policy line was identified Promotion of health and quality of life and in its national priorities in health, in this sense, it is established that chronic or communicable diseases have mechanisms to determine compliance with the norms and procedures in health promotion and disease prevention, through strategies that value individual and collective behaviors in relation to health as fundamental ; these are determinants in the appearance of chronic diseases, among others as a result of the demographic transition, unhealthy habits of life, consumption of addictive substances and that act as responsible for the increase of the burden of diseases of cardiovascular origin. The therapeutic adherence is defined by OMS, ${ }^{1}$ through the fusion of the concepts delivered by Haynes RB \& Rand CS, et al.,,3 as " The degree to which the behavior of a person - taking the medication, following a diet and carrying out lifestyle changes corresponds to the agreed recommendations of a healthcare provider - "Several studies agree that there are four variables and within multiple factors associated with adherence, these include: variables of the patient, the disease, the treatment and the relationship. According to data registered by the WHO, (2003): ${ }^{1}$

"Despite effective treatment, half of patients treated for hypertension completely abandon care after the first year of diagnosis (15) and, of those who remain under medical supervision; only 50\% 
take at least $80 \%$ of their prescribed medications. ${ }^{4}$ Consequently, due to poor adherence to antihypertensive treatment, approximately $75 \%$ of patients diagnosed with hypertension do not achieve optimal blood pressure control Burt VL, et al., ${ }^{5}$ and Costa FV. (nineteen ninety six). " 6

Table 2 Lack of adherence to the treatment of the arterial hypertension program IPS Level II

\section{Lack of adherence to $L$ treatment program arterial HYPERTENSION - HTA -}

\section{Prioritized matter}

Inapplicable care guides for HTA delivered by Ministry (2017)EGISTRATION $r$ data

for poor adherence to treatment

Little follow-up to changes in way of life

Surveillance to drug delivery

Scarce c continuous attendance

Maintenance Equipment / Shortages Supplies or elements for the program

Opportunity for drug deliveries

There is no follow-up to Hospitalized and Post / Hospitalized due to causes of increase in blood pressure

\section{Alternative of solution raised}

Medical Records track and Databases

/ Lift EGISTRATION s $r$ al adherence for a treatment, not to be confused with adherence to the program.

Support process: Medical Leader of the HTA program, Chief Nurse Program, Director of the IPS, Medical sentinel of the Quality Specialist Internist

Capture from general practice and interdisciplinary referral

Support process: Nutritionist and Psychology

Monitoring and evaluation of indicators for drug delivery

Support process: Nurse Chief of the program, Director of the IPS

Training at all levels of the organization

Support process: Program Chief Nurse, Program Leader, Nutritionist, Psychologist,

Quality Sentinel Doctor

Compliance with preventive and corrective maintenance plans:

Compliance plan of purchases and supplies

Support process: Head Nurse Program,Administrative Coordinator of La I PS Level II and IPS Director

Compliance with contractual relationships with the supplier of medicines for timely deliveries:

Coordinator of $\mathrm{P}$ and $\mathrm{P}$ of the EPS, Medical Director of the E.PS (This process is centralized in EPS)

Weekly Follow-up Committee Hospitalized and Post / Hospitalized Supports Process: Director EPS and Director of the IPS Audits of both parties

Source: Problem tree, objectives tree, problem prioritization, interest analysis matrix and logical framework matrix employees for data collection and processing.

The reality for Latin America is more daunting than the previous data, while the $\mathrm{WHO},{ }^{7}$ records data where $20 \%$ and $35 \%$ of the adult population of Latin America and the Caribbean have hypertension. It establishes that the number of people with hypertension is increasing in recent years and many are unaware of their condition. According to a study in four countries in South America (Argentina, Chile, Colombia and Brazil), only $57.1 \%$ of the adult population estimated with high blood pressure knows that they have hypertension, which contributes to the low level of population control: "Only 18.8\% of hypertensive adults in these four countries have controlled blood pressure" WHO. ${ }^{7}$ The lack of adherence is a problem that greatly concerns the health system of the countries of South America, see Figure 2. He Ministry of Health Colombia (2000) issued Resolution 412 to adopt $r$ guides attention to developing actions of specific protection and early detection and care of diseases of public health, and , in Chapter II Article 10 adopts the guide a of Arterial Hypertension as a frame of reference to apply in the IPS. In recent decades Colombia $h$ to assisted development of health practice based on valid evidence to guide decision-making. Over time, this new orientation has been expressed in the generation of evidence-based recommendations, which applied to an area or condition; together constitute clinical practice guidelines (CPG). In 2010, the Colombian government made a call to produce CPGs based on evidence for different health conditions, one of them being HTA. For the first time in the country, a common methodological approach was followed for these CPGs. In this context, the GTA of HTA was produced, which was published in 2013 and updated 2017

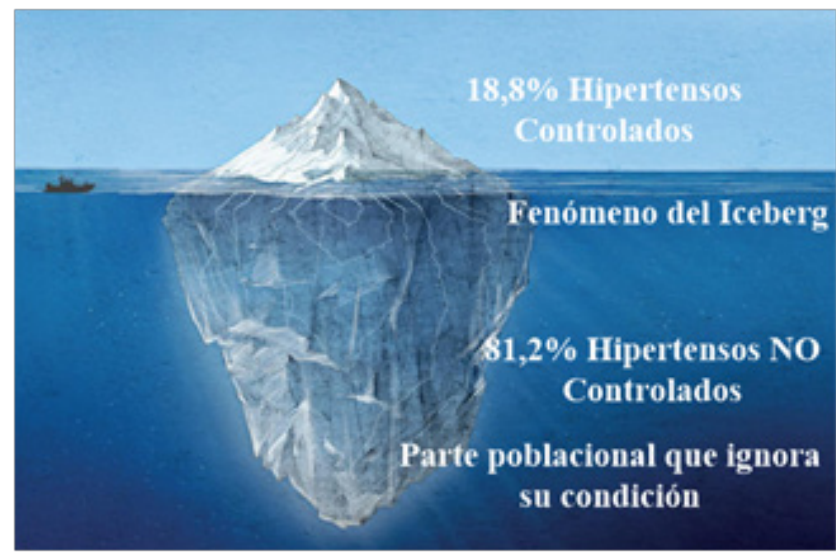

Figure 2 Reality in Control of Arterial Hypertension (Argentina, Chile, Colombia and Brazil) 2017.

Source:WHO data 2017 Adjusted to this article by the author

Image:https://www.canadiangeographic.ca/article/infographic-hownewfoundland-deals-its-yearly-iceberg-rush (Illustration: Shizuka Aoki) 


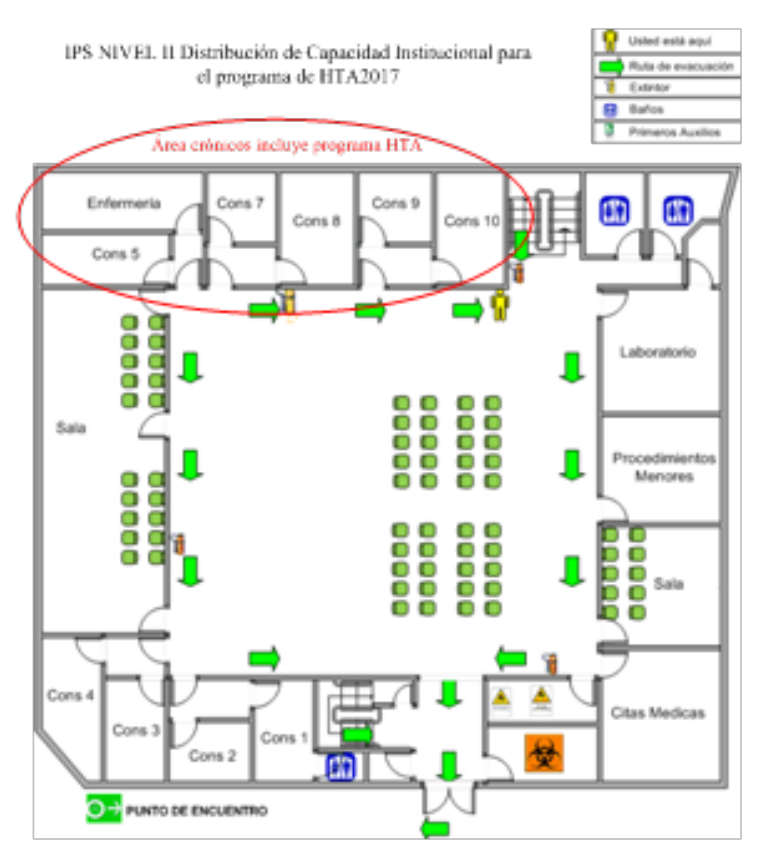

Figure 3 Distribution of Institutional Capacity HTA IPS Program Level II. Source:The present work

\section{Diagnosis identified in the IPS level II and alternative}

Related information was collected with the lack of adherence to 1 treatment of hypertensive patients IPS through a primary committee requested by the Directorate of IPS, which allowed us to go for data collection are the following reasons causes Non - adherence to treatment 1 responsible for each activity and gave proposals depending on the environment of problem solving:

\section{Capacity analysis in public health}

Public health information systems:

The information systems used in the IPS Level II for the monitoring and control of the event are: The epidemiological surveillance system - SIVIGILA - for notification of mandatory reporting events. Data bases where the daily activities carried out in the different programs are registered, such as vaccination, growth and development, prenatal control, hypertension and diabetes, so that specific data can then be filled out in the performance indicators Table.

\section{Indicator report:}

Controlled hypertensive patients $=$

$\mathrm{N}^{\circ}$ of patients enrolled with more than six months in the program and has controlled blood pressure in the last two controls according to the guide

Total number of patients with 6 months or more enrolled in the hypertension program with cut to the last day of the month evaluated. For this indicator we have a proposed goal of $45 \%$, which has not been met during 2017, demonstrating the lack of adherence to control according to the arterial hypertension program (Figure 4). It should be noted that IPS Level II measures adherence to the program, but no records are found for adherence to treatment. Items that make up the database of hypertensives are: registration date, day, month, year, full name of unknown etiology, type i DENTIFICATION, number of i DENTIFICATION, date nacimientog, January and dad, address residence, zone telephone, program physician via i ngreso -IPs, hospitalization, spontaneous, issued $\mathrm{r}$ (Another IPS, EPS)pirstez $\mathrm{v}$ in program that $\mathrm{p}, \mathrm{t}$ there, the IMC ingreso, calificación BMI CLASSIFICATION HTA, another patología, high risk criteria, hospitalizations $\mathrm{r}$ elated and controls: $\mathrm{c}$ on basic indicators for monitoring.

\begin{tabular}{|c|c|c|c|c|c|c|c|c|c|c|c|c|c|}
\hline \multirow{2}{*}{$\begin{array}{c}\text { Mfin Hipeate sos } \\
\text { control-dos }\end{array}$} & \multicolumn{12}{|c|}{ Aro 2017} & \multirow{2}{*}{ Pronedo Án } \\
\hline & Enero & Fehrero & Mara & Ahri & Mryo & Jurio & Jus & Agosto & Septiembre & Octubre & Noniembre & Diciembre & \\
\hline $45 \times$ & $\mathbf{3 1 *}$ & $33 \times$ & $30 \%$ & $32 x$ & $31 \%$ & $34 x$ & $33 \%$ & $35 \times$ & $33 \times$ & $\mathbf{3 2 x}$ & $34 x$ & $\mathbf{3 1 x}$ & 325 \\
\hline
\end{tabular}

Figure 4 Arterial hypertension program.

Source:The present work

\section{The public health workforce}

The staff that works in the IPS Level II is composed of a Director of the unit, an Administrative Coordinator, General Practitioners, Specialist Physicians of the basic specialties (Internist, Gynecologist, Pediatrician, and General Surgeon), nurses, nursing assistants, psychologist and nutritionist. It also has administrative support staff to assign and fulfill appointments, user guidance, and generation of orders. The hypertension program is coordinated by a leading physician appointed for that purpose with the support of another general practitioner, psychologist, nutritionist and nurse, a multidisciplinary team for the management and control of user morbidity. There is also the possibility of remission and control with an internist, and the advice and control of a sentinel doctor (internist who supervises the quality of the hypertension program). This offer is ideal for the operation of the hypertension program, however, despite the fact that the IPS Level II has a tool that allows the calculation of the assistance personnel as administrative necessary to have contracted according to the demand (population assigned to attend by the contributory EPS that has contracted it), due to administrative difficulties in not being agile in the hiring process and of the limited offer in the middle of the specialty of internal medicine, in case of resignation of a professional who is part of the program of hypertension is incomplete, which generates shortcomings due to not timely replacement or at the beginning of program management with other professionals who have not been trained with specific training, nor follow or abide by the specific protocols of the hypertension program, they lead to aggravate the situation of users by not encouraging adherence to the program.

\section{Institutional and organizational capacity}

The I PS Level II has specific offices for the location of the professionals in charge of the hypertension program, with the provision of biomedical and administrative equipment and necessary supplies for the care; however affected the program and therefore the proper management of morbidity and user adherence to this, due to administrative failures in preventive maintenance and calibration of equipment such as scales, sphygmomanometers, stethoscopes for lack of 1 compliance schedule established for this purpose, as there is no 
appropriation of resources (or are insufficient) to ensure the proper functioning of biomedical equipment which leads to inadequate registration of weight, blood pressure or to be missed the taking and records of these in the clinical history due to the non-possibility of using the equipment that generates inadequate control, diagnosis and treatment.

\section{Public health technologies}

They include all physical resources and technologies used in the public health system, in addition to medicines and vaccines that allow the public health system to function, such as public health laboratories, blood banks, etc. As we can see in the table, the drugs are part of assistive technologies Singles and have high influence on decision-making for adherence to treatment. The analysis of the technologies for the rational use of medicines in the patients of the HTA program of the IPS level II, is widely influenced by the issue of product cost, therefore, appreciations are collected through the traffickers related to the non-quality costs that may be directly influencing adherence due to unsuccessful control attempts that impact on patients' decisions and de-motivate traffickers. This topic is suggested for other types of research interventions because it requires deepening various variables that influence it. L to World Health Organization (2010) notes that "more than half of all drugs in the world are prescribed, dispensed or sold inappropriately, World Health Organization, ${ }^{8}$ and that half of all patients do not take their medication as prescribed or dispensed, ${ }^{1}$ Which reveals that the rational use of medicines becomes a strategy of great and positive consequences, and allows to face HTA effectively and efficiently. The critical attitude towards pharmaceutical propaganda on the part of physicians is insufficient, the internet and websites are underutilized by health professionals, it is proven that they are useful tools in aspects related to clinical pharmacology such as communication, training and research, situations that must be addressed from the scope of the EPS and with the endorsement of IPS Level II.

\section{Financial resources for public health}

The I PS Level II allocates specific resources by programs, as it captures resources for promotion and prevention and distributes them in the variety of programs offered, estimating a distribution of resources of $15 \%$ of the total for promotion and prevention for the HTA program. However, this data varies according to the flow of funds and does not represent an allocation standard. Within health expenditure, more and more attention is paid to pharmaceutical expenditure, a concern that concerns decision makers, directors, managers and/or health administrators, pharmacists and the patients themselves. For the patient, lack of adherence to 1 treatment affects invested in drug spending does not consume, the loss due to absenteeism because of uncontrolled disease, should be working, with the consequent affectation the productivity of your job. The patient's expenditure can also translate into sensitive losses to the family economy and unnecessary storage of medicines not consumed in the home, which can cause accidental poisonings in children and the increase of irresponsible self-medication by any member of the family. Expenditure by EPS is considerably increased in unused medical care, delivery of unused medications, previously planned consultations that are not executed, increased interventions, hospitalizations and increased use of services, both emergency and intensive care. A WHO report indicates that the interruption or abandonment of a therapy increases the costs of public health by at least $20 \%$ in conservative calculations. The economic benefits of good treatment adherence 1 expressed in savings from reduced use of services complex and costly health by disease progression, crisis or relapse. The indirect savings have to do with the improvement of the patient, the preservation of their quality of life and all their social, work, recreational and personal functions. The I PS Level II takes control of the cost by program and this serves as sustenance to program resources of next validity.

\section{SAW, Summary of discussion}

There are structural difficulties to integrate the actions of mandatory compliance in the programmatic axes of the Territorial Health Plan to the EPS Actions, omission in the design of the Plan to four of the six axes proposed in the standard, the design of indicators delivered in the plan does not support the established goal; As an example, in the plan it is related to the reduction of mortality from chronic diseases such as HBP in those over 45 years of age, to carry out strategies to promote healthy habits aimed at children under 10 years of age affiliated with the EPS. There is difficulty in consigning in the plan, inter-institutional actions that compromise the competition of several actors of the system, draws attention as they are not taken into account the Occupational Risk Managers -ARL- , of the Population insured by the EPS. Amounts allocated by sources of resources are not included in the Plan. It is fulfilled with the physical delivery of a $p$ lan, however it is not evident in the same integration adjusted to what is established in the norm for the development of national, departmental and local policies, much less those that integrate joint actions with 1 to I PS Level II that result in the improvement of programs such as HTA. ${ }^{9-18}$

\section{General Recommendations}

To successfully address the therapeutic adherence of hypertensive people, team work and a multidisciplinary approach are required, which allows the patient to meet the needs of the respective team professional. Perform permanent monitoring of the application of protocols and care guidelines for hypertensive patients, with support from the institutional information systems to determine the intervention areas and subsequently measure the impact of these on levels of adherence. Regarding the work force, it is convenient to improve the training, induction and reinduction plan that the institution has in such a way that the comprehension, commitment and application of the clinical guidelines of attention to hypertensive patients by all the team members is ensured of work. Motivate in encouraging timely and quality research of the work team around the problems detected with respect to adherence to treatment to assume with evidence the solution of the issues found. Monitor in a programmed manner the existence, and supply medicines for patients, and the provision and review of the proper functioning of equipment required, this to ensure quality care that will be evident in the scope of the proposed program indicators. Establish mechanisms for communication, information and timely resolution of nonconformities expressed by patients to help adhesion.

\section{Conclusion}

Institutional directives must commit to the development of strategies to improve and support workforce includes topics such as capacidades Public Health, Skills and Functions Essentials Public Health. Agreements with academic sectors and health authorities are important to coordinate these efforts. It is required that IPS Level II formulates clear policies in terms of Public Health Management, which will make it possible to demonstrate in their personal knowledge and attitudes to it. Factors associated with no adherence to treatment from 1 Public Health capacities are multiples according to the study, as well as the causes of not following the treatment established in the problem tree and defined in the objectives tree. Some issues that should be addressed in a special 
way by the managers and administrators of the health system of the EP S and the I PS are discussed in the present document; and are a demonstration that the issue is due to a serious health problem for Public.

\section{Acknowledgements}

None.

\section{Conflict of interest}

The author declares there is no conflict of interest.

\section{References}

1. OMS. Adherence to long-term therapies: evidence for action. Edited by Eduardo Sabaté, World Health Organization. 2003.

2. Haynes RB. Determinants of compliance: the disease and the mechanics of treatment. Baltimore (MD): Johns Hopkins University Press, 1979. p. 49-62.

3. Rand CS. Measuring adherence with therapy for chronic diseases: implications for the treatment of heterozygous familial hypercholesterolemia. American Journal of Cardiology. 1993;72(10):68D-74D.

4. Mapes REA. Physician's drug innovation and relinquishment. Social Science \& Medicine. 1977;;11(11):619-24.

5. Burt VL, Whelton P, Roccella EJ, et al. Prevalence of hypertension in the US adult population: results from the Third National Health and Nutrition Examination Survey, 1988-1991. Hypertension. 1995;25(3):305-313.

6. Costa FV. Compliance with Antihypertensive Treatment. Clinical and Experimental Hypertension. 1996;18 (3-4):463-72.

7. OMS. Día mundial de la hipertensión 2017. Conoce tus números. 2007.

8. World Health Organization. Medicines use in primary care in developing and transitional countries: fact book summarizing results from studies reported between 1990 and 2006 (No. WHO/EMP/MAR/2009.3). Geneva: World Health Organization. 2009.
9. Departamento Administrativo de Planeación. Cali en Cifras. Edición: Subdirección de Desarrollo Integral-DAP. Imprenta Departamental. 2016.

10. Martín Alfonso L, Bayarre Vea H, La Rosa Matos Y, et al. Cumplimiento e incumplimiento del tratamiento antihipertensivo desde la perspectiva del paciente. Rev cub salud pública. 2007;33(3).

11. Ministerio de Salud Colombia. Resolución 412 Tomo I y II. 2000.

12. Ministerio de Salud y Protección Social. Guía de Práctica Clínica (GPC) Hipertensión arterial primaria (hta). 2017.

13. OMS. El incumplimiento del tratamiento prescrito para las enfermedades crónicas es un problema mundial de gran envergadura. Disponible. 2003

14. OMS. Adherencia a los tratamientos a largo plazo. Pruebas para la acción (Documento OMS traducido). Ginebra: Organización Mundial de la Salud. 2003.

15. Organización Panamericana de la Salud. Capacidades en salud pública en América Latina y el Caribe: evaluación y fortalecimiento. Washington, D.C: OPS. Biblioteca Sede OPS - Catalogación en la fuente. 2007. p. 1-90.

16. Organización Panamericana de la Salud, Organización Mundial de la Salud. Resolución CD50.R7 Estrategia para el Desarrollo de Competencias del Personal de Salud en los Sistemas de Salud Basados en la Atención Primaria de Salud. $50^{\circ}$ Consejo Directivo, $62^{\mathrm{a}}$ Sesión del Comité Regional. Washington. DC. EUA. 2010.

17. Suárez CJ, Godue C, Gutiérrez G, et al. Competencias esenciales en salud pública: un marco regional para las Américas. Revista Panamericana de Salud Pública. 2013;34:47-53.

18. World Health Organization. Informe Sobre la Salud en El Mundo: La Financiación de los Sistemas de Salud-El Camino Hacia la Cobertura Universal. World Health Organization. 2010. 